\title{
Communication \\ Effect of Bead Composition, PVS Type, and Recovery Medium in Cryopreservation of Bleeding Heart 'Valentine'-Preliminary Study
}

\author{
Dariusz Kulus@ \\ Laboratory of Ornamental Plants and Vegetable Crops, Faculty of Agriculture and Biotechnology, \\ UTP University of Science and Technology in Bydgoszcz, Bernardyńska 6, 85-029 Bydgoszcz, Poland; \\ dkulus@gmail.com
}

Received: 31 May 2020; Accepted: 21 June 2020; Published: 23 June 2020

\begin{abstract}
Bleeding heart (Lamprocapnos spectabilis (L.) Fukuhara) is a valuable ornamental and medicinal perennial. To date, there are few studies focused on cryopreservation of this species, although it could be useful in storage and breeding. This research is aimed at analyzing the effect of bead composition, type of plant vitrification solution (PVS), and the recovery medium of cryopreservation of bleeding heart. Shoot tips of L. spectabilis 'Valentine' were used in the study. The explants were precultured on modified Murashige and Skoog medium (MS; 1962), supplemented with $9 \%$ sucrose, 1.0-mg. $\mathrm{L}^{-1}$ kinetin (KIN), and 2.62-mg. $\mathrm{L}^{-1}$ abscisic acid. Next, in the first experiment, the shoot tips were embedded in 3\% calcium alginate, based either on an MS medium or distilled sterile water. The produced synseeds were inoculated on the recovery medium with $3.0-\mathrm{mg} \cdot \mathrm{L}^{-1} \mathrm{KIN}$, 0.5-mg $\cdot \mathrm{L}^{-1}$ 6-benzyladenine (BA), or cytokinin-free control. Based on the results of the first study, in the second experiment, precultured shoot tips were embedded in $3 \%$ calcium alginate based on MS medium and dehydrated with PVS2 or PVS3 for various durations. The pre-treated explants were plunged in liquid nitrogen and, after rewarming, inoculated on the recovery MS medium with $0.5-\mathrm{mg} \cdot \mathrm{L}^{-1}$ BA. PVS3 was more effective in securing the shoot tips than PVS2. The highest recovery level $(68.3 \%)$ was reported after a 150-min pretreatment with PVS3. Explants from this experimental combination also proliferated the highest number of shoots, as well as those with the greatest length. On the other hand, a higher share of dry weight was found in PVS2-derived shoots (13.5-18.2\%) compared with plants produced after PVS3 treatment (10.6-11.4\%). The obtained results here can serve as a good basis for further studies related to synthetic seeds and cryopreservation of bleeding heart.
\end{abstract}

Keywords: alginate; cytokinin; encapsulation-vitrification; Lamprocapnos spectabilis; long-term storage; tissue culture

\section{Introduction}

The bleeding heart (Lamprocapnos spectabilis (L.) Fukuhara) is a root perennial from the family Fumariaceae, originating in China and Japan [1]. It owes its name to the extraordinary shape of the flowers, which look like a heart with a variety of colors from white through pink to red. In nature, it can be found in the forests of North America and Asia where it forms magnificent clumps. The species is highly appreciated in the pharmaceutical, horticultural, and floristic markets [2,3]. Unfortunately, there are just a few studies related to biotechnology and tissue culture of bleeding heart [4-6].

In-vivo cultivation of L. spectabilis is hampered by weeds, numerous pathogens, and pests, i.e., thrips (Thripidae), whiteflies (Aleyrodidae), slugs and snails (Gastropoda), Fusarium spp., fungal leaf spots (Stemphyllium), southern blight (Sclerotium rolfsii Sacc.), gray mold (Botrytis cinerea Pers.), tobacco rattle tobravirus (which is the most devastating among viruses), tobacco ringspot nepovirus, 
tobacco mosaic virus, ribgrass mosaic virus, and the aster yellows phytoplasma [2]. All of them can cause severe plant losses. Maintenance of in-vivo collections is also labor intensive. Moreover, due to the changing climate conditions, resulting in prolonged drought and other abiotic stresses [7], one of the most urgent needs is to develop effective long-term storage methods of species genetic resources.

The easiest way to conserve plant germplasm is to collect seeds in gene banks. However, this is not the case with bleeding heart. Members of the Fumariaceae family have some of the most complex and extended germination patterns in the plant kingdom [8]. Bleeding heart produces recalcitrant seeds, for which drying is either fatal or severely deleterious [8]. Moreover, offspring do not have the same genetic set up when propagated by seed. In-vitro, slow-growth conservation is possible [9], but it comes with a cost and the possibility that somaclonal variation will occur over time [10]. Cryopreservation can solve these issues and allows us to store plant genetic resources at the ultra-low temperature of liquid nitrogen (LN), at which biological and chemical activities are halted.

An encapsulation-dehydration cryoprotocol has been described for bleeding heart [11]. This method, however, is time consuming, and its effectiveness is limited (survival $<40 \%$ ). Therefore, other techniques based on dehydration with plant vitrification solutions (PVS) should be considered. PVSs are aqueous solutions of penetrating and nonpenetrating cryoprotectants, which can be cooled to temperatures below the glass transition temperature without intracellular or extracellular ice formation [12]. The most popular PVS (PVS2) was optimized by Prof. Akira Sakai in 1990 for cooling citrus callus and consists of 30\% glycerol, 15\% ethylene glycol, 15\% dimethyl sulfoxide (DMSO), and $0.4 \mathrm{M}$ sucrose. PVS2 easily supercools below $-100{ }^{\circ} \mathrm{C}$ upon rapid cooling and 'solidifies' into a metastable glass at about $-115^{\circ} \mathrm{C}$ [13]. DMSO, however, may be toxic for the cells and/or affect the structure of chromosomes and expression of genes [14]. Ethylene glycol, on the other hand, can lead to premature senescence of tissues [15]. In 1993, Nishizawa et al. [16] developed PVS3 (50\% glycerol and $50 \%$ sucrose), which is preferred for explants that are damaged by DMSO. The final decision on PVS type, concentration, and exposure duration is species- and explant-type-dependent [17]. Other important elements of a cryopreservation protocol that require consideration are the composition of the bead matrix (in case of encapsulation-based techniques) and selection of plant growth regulators (PGRs) in the recovery medium, as they directly affect the postcryopreservation reaction of explants [17]. Therefore, the aim of this study was to analyze for the first time the effect of bead composition, type of PVS, and recovery medium in cryopreservation of bleeding heart.

\section{Materials and Methods}

\subsection{Plant Material and General In-Vitro Culture Conditions}

Lamprocapnos spectabilis 'Valentine' shoot tips with 2-3 young leaves covering the meristem (1.0-2.0 $\mathrm{mm}$ in length) were used in the experiments.

Plant material was multiplied by cutting into $1.0-\mathrm{cm}$-long nodal segments and cultured on modified MS medium [18] with extra 330-mg. $\mathrm{L}^{-1}$ calcium II chloride $\left(\mathrm{CaCl}_{2} \cdot 6 \mathrm{H}_{2} \mathrm{O}\right), 13.9-\mathrm{mg} \cdot \mathrm{L}^{-1}$ iron sulfate $\left(\mathrm{FeSO}_{4}\right), 55.8-\mathrm{mg} \cdot \mathrm{L}^{-1} \mathrm{Na}_{2} \mathrm{EDTA} \cdot 2 \mathrm{H}_{2} \mathrm{O}$, and $3.0-\mathrm{mg} \cdot \mathrm{L}^{-1}$ kinetin $(\mathrm{KIN})$. Plant growth regulators were provided by Sigma-Aldrich ${ }^{\circledR}$, St. Louis, MO, USA.

Cultures were kept in the growth room at $23{ }^{\circ} \mathrm{C} \pm 1{ }^{\circ} \mathrm{C}$, under 16 -h photoperiod conditions and photosynthetic photon flux density of approximately $30 \mu \mathrm{mol} \cdot \mathrm{m}^{-2} \cdot \mathrm{s}^{-1}$ provided by standard cool daylight TLD 54/36W fluorescent tubes (Philips Electronics N.V., Eindhoven, the Netherlands).

\subsection{Preculture}

To produce and harden the shoot tips, in-vitro-derived single node explants with removed leaves were cultured for one week on modified MS medium with $9 \%$ sucrose, $1.0-\mathrm{mg} \cdot \mathrm{L}^{-1} \mathrm{KIN}$, and 2.62-mg. $\mathrm{L}^{-1}$ of abscisic acid (ABA). The medium was solidified with $0.8 \%$ agar (Biocorp, Warsaw, Poland). The $\mathrm{pH}$ was adjusted to 5.8 after adding all media components (Chempur, Piekary Ślaskie, Poland) before 
autoclaving at $105 \mathrm{kPa}$ and $121^{\circ} \mathrm{C}$ for $20 \mathrm{~min}$. The media (30-mL) were distributed into 350-mL glass jars and sealed with plastic caps. Ten explants were inoculated polarly into one jar.

\subsection{Experiment I: Comparison of Bead Matrix and Culture Medium Composition on the Recovery of Non-LN-Stored Shoot Tips of Bleeding Heart}

Precultured shoot tips were excised and embedded for $10 \mathrm{~min}$ in 3\% sodium-alginate (Carlo Erba, Val-de-Reuil, France), based either on the modified MS medium salts (as described above, without $\mathrm{CaCl}_{2}$ ) or distilled water, supplemented with $9 \%$ sucrose. Then, the beads, $3-4 \mathrm{~mm}$ in diameter, were hardened in $100-\mathrm{mM} \mathrm{CaCl}_{2}$ solution for $30 \mathrm{~min}$. The encapsulated explants were rinsed three times with distilled sterile water and inoculated on the 30-mL modified MS recovery medium fortified with 3.0-mg. $\mathrm{L}^{-1} \mathrm{KIN}, 0.5-\mathrm{mg} \cdot \mathrm{L}^{-1}$ 6-benzyladenine (BA), or PGRs-free control in a 90-mm Petri dish sealed with a parafilm with 10 explants per dish.

\subsection{Experiment II: Comparison of PVS2 and PVS3 Effectiveness in Cryopreservation of Bleeding Heart}

Precultured shoot tips were excised and embedded in $3 \%$ calcium alginate based on the modified MS medium salts (as described above) and osmoprotected with loading solution (2.0 M glycerol and $0.4 \mathrm{M}$ sucrose) for $20 \mathrm{~min}$. Next, the explants were dehydrated with $1 / 2$ (half-strength) PVS2 (for 10-90 $\mathrm{min}$ ), PVS2 (10-180 $\mathrm{min}$ ), or PVS3 (120-180 $\mathrm{min}$ ) at room temperature. Ten beads were placed in a 2.0-mL sterile cryovial and immersed in LN.

After one hour of storage, the cryovials were removed from LN and rewarmed in a water bath at $39 \pm 1{ }^{\circ} \mathrm{C}$ for $3 \mathrm{~min}$. The explants were rinsed with washing solution (liquid MS medium with $1.2 \mathrm{M}$ sucrose) for $20 \mathrm{~min}$. Next, the shoot tips were inoculated on the 30-mL modified MS recovery medium with $3 \%$ sucrose and $0.5-\mathrm{mg} \cdot \mathrm{L}^{-1} \mathrm{BA}$ in a $90-\mathrm{mm}$ Petri dish. The cultures were kept in the same growth room, in darkness. After 48 hours, the explants were transferred to a 16-h photoperiod and kept at the light intensity of approximately $15 \mu \mathrm{mol} \cdot \mathrm{m}^{-2} \cdot \mathrm{s}^{-1}$ for 5 days. One week after rewarming, the shoot tips were cultured under initial lighting conditions.

\subsection{Survival and Biometrical Analyses}

Recovery of the explants (i.e., their ability to form shoots) was evaluated 45 days after culture initiation. The number, length, fresh weight (FW) and dry weight (DW) of shoots, as well as the number of leaves, were estimated. To analyze DW, shoots were desiccated in a laboratory oven at $105^{\circ} \mathrm{C}$ for $180 \mathrm{~min}$. The share of explants regenerating adventitious roots was also counted.

\subsection{Statistical Analysis}

The first experiment, regarding the composition of the bead matrix and recovery medium without subsequent LN storage, included six combinations (10 explants per combination). The second experiment studied 18 combinations (10 explants per combination). The experiments were repeated twice; a total of 480 explants were used.

The results (completely randomized design) were statistically analyzed with the one-way analysis of variance, and the comparison of means was made with Fisher's test $(p \leq 0.05)$ using Statistica 12.0 and ANALWAR-5.2-FR software.

\section{Results}

\subsection{Experiment I: Comparison of Bead Matrix and Culture Medium Composition on the Recovery of} Non-LN-Stored Shoot Tips of Bleeding Heart

It was found that, despite the presence of KIN in the medium, precultured shoot tips developed slower (no signs of first leaf development) compared with nodal segments grown on the standard MS medium with 3\% sucrose, which develop a visible leaf after one week of culture (Figure 1a,b). This growth retardation on the preculture medium can be explained by the high $(9 \%)$ 
sucrose concentration causing osmotic pressure and the presence of ABA, which is considered a dormancy hormone.
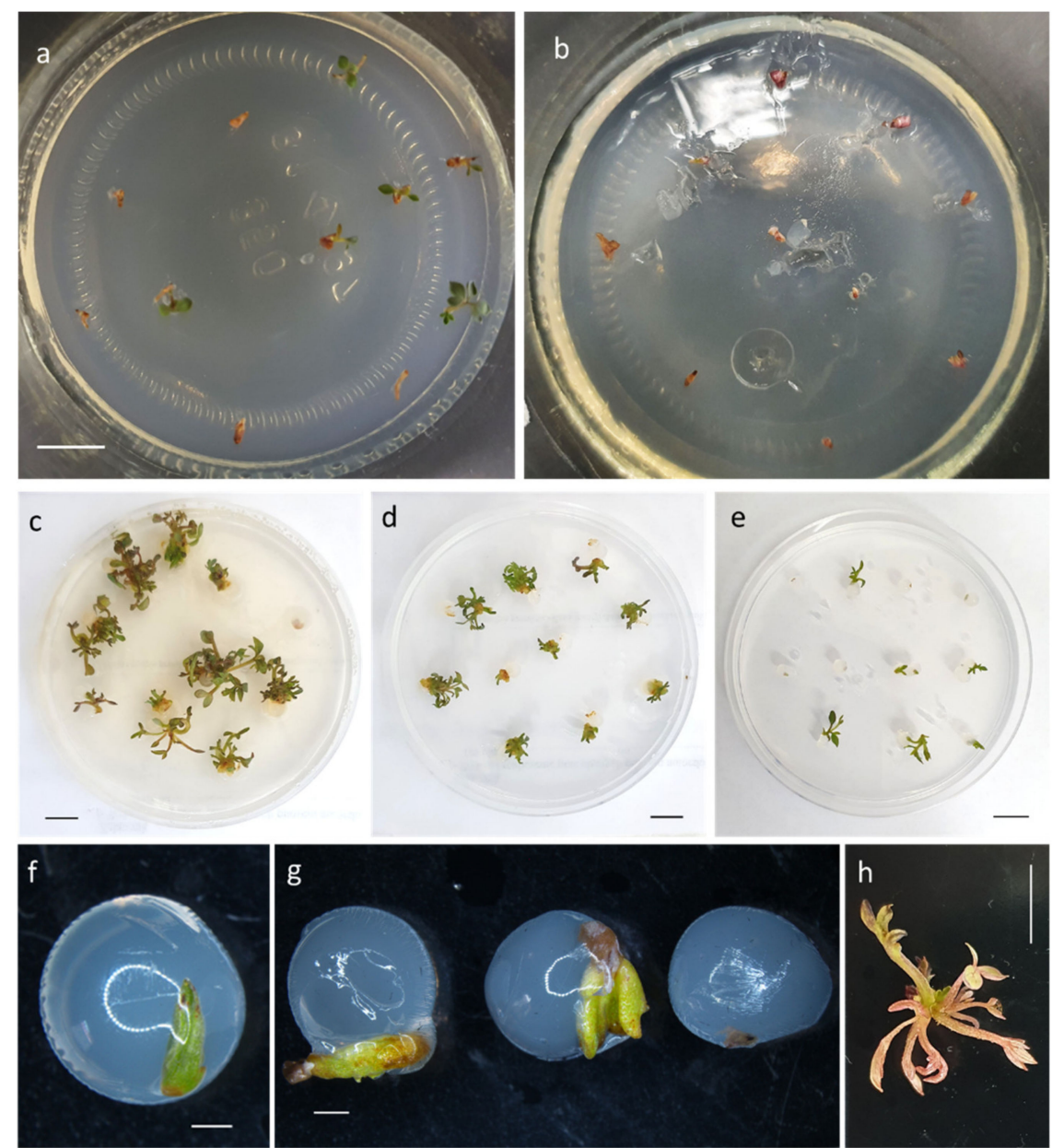

Figure 1. Development of shoot tips of Lamprocapnos spectabilis 'Valentine' after various steps of an encapsulation-vitrification protocol: (a) control nodal segments after 7-day culture on the standard Murashige and Skoog medium (MS) medium with 3\% sucrose with evident leaf development; (b) nodal segments after 7-day preculture on the MS medium with 1.0-mg. $\mathrm{L}^{-1}$ kinetin (KIN), 2.62-mg. $\mathrm{L}^{-1}$ abscisic acid (ABA), and 9\% sucrose; (c-e) development of precultured-encapsulated explants on the recovery MS media with 0.5-mg. $\mathrm{L}^{-1}$ BA or 3.0-mg. $\mathrm{L}^{-1} \mathrm{KIN}$ or plant growth regulators (PGRs)-free control, respectively, after 25 (e) and 45 (c,d) days; (f) viable but not growing shoot tip encapsulated in $3 \%$ calcium alginate (based on water) and cultured on PGRs-free MS medium for 45 days; (g) viable LN-derived shoot tips are green with clear signs of leaf development after 30 days of recovery culture, while dead explants are brown; (h) fully developed shoot after cryopreservation with 150-min PVS3 exposition and 45-day recovery on MS medium with $0.5-\mathrm{mg} \cdot \mathrm{L}^{-1}$ BA. Bar $=1 \mathrm{~cm}$, except for Figure $1 \mathrm{f}$, $1 \mathrm{~g}$ where bar $=1 \mathrm{~mm}$.

The development of encapsulated shoot tips began two weeks after recovery culture initiation. Explants embedded in the MS-supplemented matrix developed more intensively compared to the $\mathrm{H}_{2} \mathrm{O}$-based control. The highest recovery rates (75.8-81.3\%) were reported with the shoot tips encapsulated in the MS-fortified bead matrix and cultured on cytokinin-supplemented media (Table 1; Figure 1c,d). On the other hand, less than half of the explants $(43.6 \%)$ recovered shoots when only water was added into the capsule and with no PGRs in the recovery medium (Figure 1e). The remaining shoot tips either turned brown and died or remained green but did not develop (Figure 1f). 
Table 1. Influence of bead matrix composition and recovery medium on the recovery level of non-liquid nitrogen (LN)-stored shoot tips, number of shoots and leaves produced per single explant, shoot length, dry and fresh weight, and rooting efficiency.

\begin{tabular}{|c|c|c|c|}
\hline \multirow{2}{*}{ Bead Composition } & \multicolumn{3}{|c|}{ Recovery Medium Composition } \\
\hline & BA & KIN & MS0 \\
\hline & \multicolumn{3}{|c|}{ Recovery [\%] } \\
\hline alginate + MS & $75.8 \mathrm{a}$ & $81.3 \mathrm{a}$ & $52.4 \mathrm{bc}$ \\
\hline \multirow[t]{2}{*}{ alginate $+\mathrm{H}_{2} \mathrm{O}$} & $57.2 \mathrm{~b}$ & $58.8 \mathrm{~b}$ & $43.6 \mathrm{c}$ \\
\hline & \multicolumn{3}{|c|}{ Number of shoots } \\
\hline alginate + MS & $1.8 \pm 0.2 \mathrm{ab}$ & $2.0 \pm 0.2 \mathrm{a}$ & $1.0 \pm 0.0 \mathrm{c}$ \\
\hline \multirow[t]{2}{*}{ alginate $+\mathrm{H}_{2} \mathrm{O}$} & $1.5 \pm 0.1 \mathrm{~b}$ & $1.9 \pm 0.1 \mathrm{a}$ & $1.0 \pm 0.0 \mathrm{c}$ \\
\hline & \multicolumn{3}{|c|}{ Shoot length [mm] } \\
\hline alginate + MS & $14.0 \pm 1.3 \mathrm{a}$ & $9.0 \pm 0.9 c$ & $11.9 \pm 0.3 \mathrm{ab}$ \\
\hline \multirow[t]{2}{*}{ alginate $+\mathrm{H}_{2} \mathrm{O}$} & $10.2 \pm 0.8 \mathrm{bc}$ & $8.6 \pm 0.6 c$ & $11.8 \pm 0.5 \mathrm{ab}$ \\
\hline & \multicolumn{3}{|c|}{ Number of leaves } \\
\hline \multirow{3}{*}{$\begin{array}{c}\text { alginate }+\mathrm{MS} \\
\text { alginate }+\mathrm{H}_{2} \mathrm{O}\end{array}$} & $6.9 \pm 0.4 \mathrm{a}$ & $5.8 \pm 0.3 \mathrm{ab}$ & $3.7 \pm 0.1 \mathrm{c}$ \\
\hline & $5.1 \pm 1.1 \mathrm{a}-\mathrm{c}$ & $3.8 \pm 0.1 \mathrm{c}$ & $4.0 \pm 0.4 \mathrm{bc}$ \\
\hline & \multicolumn{3}{|c|}{ Fresh weight [mg] } \\
\hline alginate + MS & $102.8 \pm 12.2 \mathrm{a}$ & $34.1 \pm 2.2 \mathrm{bc}$ & $10.2 \pm 1.2 \mathrm{~d}$ \\
\hline \multirow[t]{2}{*}{ alginate $+\mathrm{H}_{2} \mathrm{O}$} & $83.6 \pm 8.7 \mathrm{a}$ & $46.1 \pm 2.2 b$ & $16.8 \pm 0.9 \mathrm{~cd}$ \\
\hline & \multicolumn{3}{|c|}{ Share of DW in FW [\%] } \\
\hline alginate + MS & $9.4 \mathrm{~b}$ & $12.5 \mathrm{a}$ & $12.6 \mathrm{a}$ \\
\hline \multirow[t]{2}{*}{ alginate $+\mathrm{H}_{2} \mathrm{O}$} & $11.6 \mathrm{ab}$ & $11.6 \mathrm{ab}$ & $8.6 \mathrm{~b}$ \\
\hline & \multicolumn{3}{|c|}{ Rooting [\%] } \\
\hline alginate + MS & $33.6 \mathrm{a}$ & $0.0 \mathrm{~b}$ & $0.0 \mathrm{~b}$ \\
\hline alginate $+\mathrm{H}_{2} \mathrm{O}$ & $20.0 \mathrm{ab}$ & $0.0 \mathrm{~b}$ & $0.0 \mathrm{~b}^{1}$ \\
\hline
\end{tabular}

1. Means \pm standard errors marked with the same letter do not differ significantly at $p \leq 0.05$ according to Fisher's test.

Kinetin was superior in stimulating shoot proliferation (1.9-2.0), while single shoots were formed in the MS0 medium (Table 1). The longest shoots were produced in the experimental combination with MS salts in the bead matrix and BA in the recovery medium $(14.0 \mathrm{~mm})$. The shortest shoots (8.6-9.0 $\mathrm{mm}$ ) were produced in the presence of KIN in the medium, regardless of the bead composition. More leaves (5.8-6.9) were produced after adding MS salts into the bead matrix and cytokinins into the medium, but also, in the experimental combination with water in the capsule and BA in the medium (5.1). The highest fresh weight of shoots was reported after adding BA into the recovery medium, while the lowest was reported in the PGRs-free control, regardless of bead matrix composition. On the other hand, the highest share of DW (12.5-12.6\%) was found in shoots recovered from explants encapsulated in the MS-fortified matrix and cultured in the medium with KIN or PGRs-free control. Rooting was stimulated by the presence of BA in the culture medium, while no roots were regenerated in the other treatments (Table 1).

\subsection{Experiment II: Comparison of PVS2 and PVS3 Effectiveness in Cryopreservation of Bleeding Heart}

The recovery of shoots was evident three weeks after the rewarming of explants. Viable explants started to develop the first leaf, while the dead ones turned brown (Figure 1g). PVS3 was more effective in securing the viability of the shoot tips (47.7-68.3\% recovery rate) compared to PVS2 (22.9-47.3\%). The highest recovery level (68.3\%) was reported after 150-min pretreatment with PVS3. None of the shoot tips pre-treated with half-strength PVS2 survived storage in liquid nitrogen (Figure 2). 

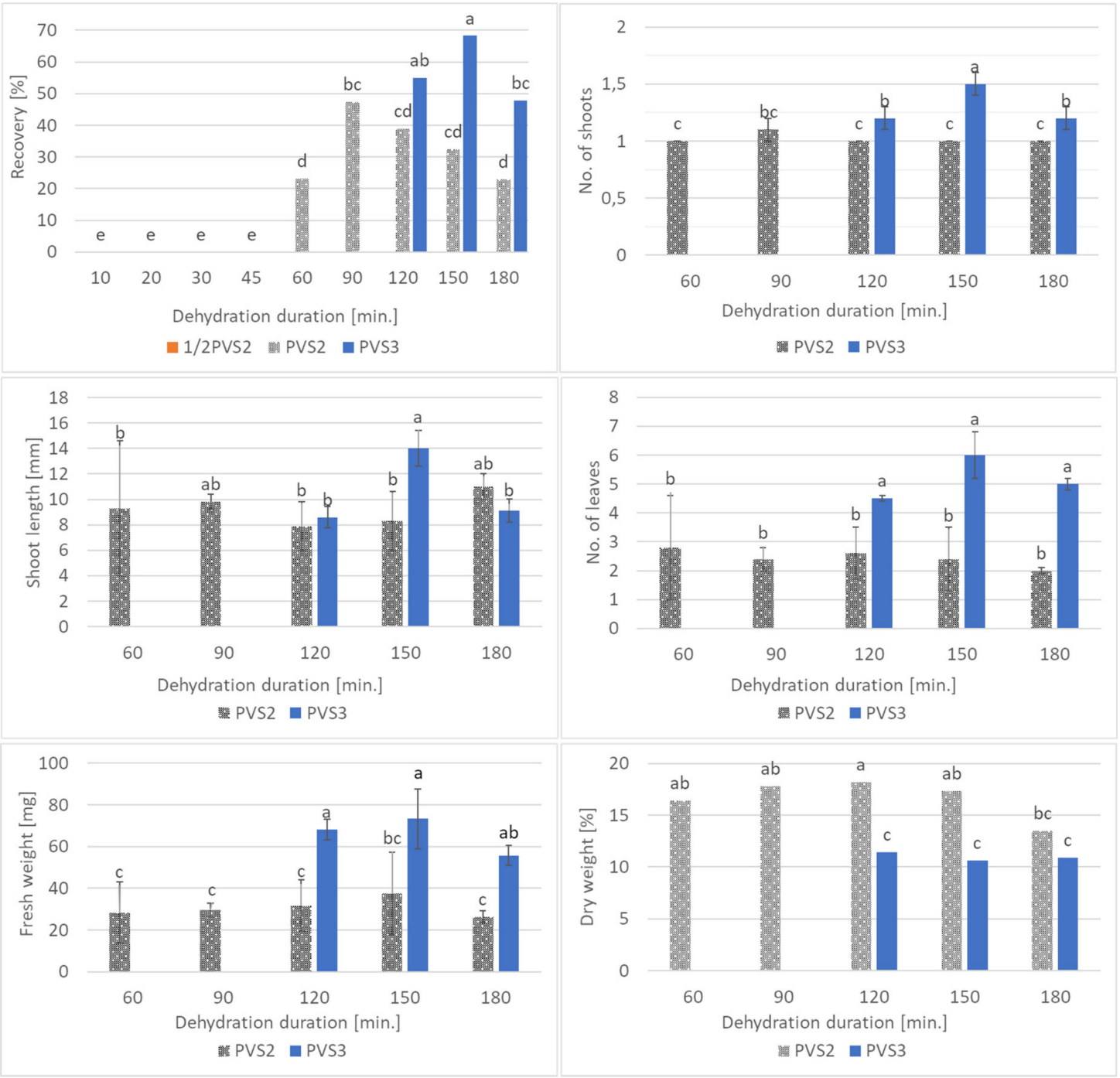

Figure 2. Influence of plant vitrification solution (PVS) type and exposure duration on the recovery level of cryopreservation-derived shoot tips, number of shoots and leaves produced per single viable explant, shoot length, fresh, and dry weight. Means \pm standard errors marked with the same letter do not differ significantly at $p \leq 0.05$ according to Fisher's test.

The experimental combination with 150-min PVS3 treatment was optimal in terms of shoot proliferation (1.5 per explant) and shoot length $(14 \mathrm{~mm}$ ) (Figure 2). Shoots derived from PVS3-treated explants produced more leaves (4.5-6.0) than those dehydrated with PVS2 (2.0-2.8). Moreover, the fresh weight of shoots was higher after PVS3 exposure (55.7-73.3-mg) compared with PVS2 treatment (26.4-37.5-mg). On the other hand, shoots dehydrated with PVS2 usually had a higher share of dry weight (16.4-18.2\%) than those treated with PVS3 (10.6-11.4\%), except for 180-min dehydration (Figure 2). The resulting shoots displayed normal growth habits relative to non-LN-stored controls (Figure 1h). However, none of the cryopreservation-derived shoots produced roots.

\section{Discussion}

In the present study, a positive influence of BA and KIN on the recovery level of encapsulated shoot tips in L. spectabilis 'Valentine' was found. In four chrysanthemum cultivars of the Lady group, the addition of those cytokinins into the culture medium was also necessary to stimulate the germination of synthetic seeds [19]. Cytokinins, N6-substituted derivates of adenine, promote photosynthesis, growth, and differentiation of cells [20], which could explain the present results. Similarly, the addition 
of MS salts into the bead matrix positively affected the recovery of shoots in bleeding heart, probably due to easier access to nutrients in the artificial endosperm. Surprisingly, KIN reduced the length of shoots $(8.6-9.0 \mathrm{~mm}$ ) compared to those from the PGRs-free control medium (11.8-11.9 mm). Usually, this cytokinin is involved in cell elongation and activation of existing meristems. In the present study, explants inoculated on the medium with KIN produced twice as many shoots (1.9-2.0) compared to MS0 (1.0), which could explain their shorter length. Interestingly, in this research, despite the high fresh weight of shoots produced on the BA-supplemented medium, a higher share of DW was found in the presence of KIN and PGRs-free control, especially if MS salts were added into the bead matrix (12.5-12.6\%). A higher level of hydration resulting from the long BA treatment was previously reported with Aloe polyphylla Schönland meristems by Ivanova and Van Staden [21]. This problem could be overcome by shortening the BA treatment or lowering its concentration in the medium. In several plant species, it was reported that optimal root formation occurred in the presence of auxins and cytokinins [22]. With bleeding heart, BA was more effective in stimulating rooting than KIN or MS0 medium. As for cherry shoots (Prunus avium L.), up to 70-100\% rhizogenesis efficiency was found on the medium with $0.1 \mathrm{mg} \cdot \mathrm{L}^{-1} \mathrm{BA}$, although similar frequency was found on the PGRs-free control [23]. As for chrysanthemum synseeds, KIN was more effective in stimulating rooting than BA [19]. This highlights the species dependency effect of PGRs.

The success of cryopreservation strongly depends on the procedure used for adapting plant material to cryogenic storage. The methods used in this study have proven effectiveness, as even $68.3 \%$ of shoot tips survived and recovered after LN storage. Those results are better compared with cryopreservation of ajania 'Bengo' shoot tips ( $8.3 \%$ regrowth) and protocorm-like bodies (PBLs) of some orchid species (5-20\% regeneration) [24-26]. Generally, the viability of bleeding heart explants was stable throughout the entire postrewarming observation period. This fact is important, as survival does not always equal plantlet regrowth as reported by Kulus et al. [27]. In the present study, however, the LN-derived viable shoot tips undertook their native program of development continuation.

PVS3 was more effective in cryopreservation of bleeding heart shoot tips than PVS2 in terms of survival and biometrical parameters of shoots produced. This coincides with the findings of Kim et al. [12] in garlic and chrysanthemum in a droplet-vitrification procedure. Additionally, in Allium cepa L. cryopreserved samples, exposure to PVS3 provided a broader safe-temperature range $\left(-196{ }^{\circ} \mathrm{C}\right.$ to $\left.-88^{\circ} \mathrm{C}\right)$, compared to that $\left(-196{ }^{\circ} \mathrm{C}\right.$ to $\left.-116{ }^{\circ} \mathrm{C}\right)$ of PVS2 [28]. In contrast, the highest recovery rates for both Passiflora suberosa L. and P. foetida L. (28\% and 60\%) were reported with the encapsulation-vitrification protocol after pretreatment with 0.3-M sucrose, followed by exposure to PVS2 for 60 or $120 \mathrm{~min}$, respectively [29]. Low recovery rates of explants pretreated with PVS2 in the present study $(22.9-47.3 \%)$ may be either due to toxicity from exposure to cryoprotectant solutions; specifically, DMSO has been noted for its cytotoxicity [28] and insufficient protection against freezing injury. This hypothesis is supported by the increase in the DW content in PVS2-treated shoots, which might be a result of stress and defense reaction of the cell manifested by the accumulation of lignin and various osmoprotectants in the cell wall [30,31]. Analyzing the dynamics of survival change in relation to PVS2-treatment duration, it can be concluded that optimal dehydration was obtained after $90 \mathrm{~min}$ of exposure; both shorter and longer expositions were less effective (recovery levels below the so-called "safe limit" of 40\%). As for PVS3, a broader safe duration range (120-180 min) was found. Half-strength PVS2 was not able to dehydrate the cells sufficiently enough as no survival was reported in those combinations, regardless of exposition time. Since the regrowth level of non-LN-stored shoot tips reached up to $81.3 \%$, the impact of mechanical damage during excision can be considered minimal.

It is believed that cryopreservation does not affect the parameters of stored biological material. Previous research demonstrated no impact of the encapsulation-based cryoprotocols on the genetic stability in L. spectabilis [11]. However, in the present study, slower development of cryopreservation-derived shoot tips was reported (growth was evident one week later than in the precultured-encapsulated but non-LN-stored samples and two weeks later than in the non-treated "naked" explants). There were also no roots found in cryopreservation-derived shoots in contrast 
to non-LN-stored samples cultured in the same recovery medium. Similarly, control shoots of Rosa dumalis Bechst. and R. rubiginosa L. rooted better than postcryopreserved shoots, while there were no differences in rooting between the control and cryopreservation-derived shoots of $R$. agrestis Savi and R. canina L. [32]. Therefore, the behavior and functionality of bleeding heart plants recovered from cryopreserved samples should be monitored once they are reintroduced into the natural environment.

\section{Conclusions}

Supplementation of the bead matrix with MS salts and the addition of $0.5-\mathrm{mg} \cdot \mathrm{L}^{-1}$ BA into the germination medium is recommended with synthetic seeds of Lamprocapnos spectabilis 'Valentine'. Moreover, PVS3 is more suitable than PVS2 in the cryopreservation of bleeding heart by providing a better survival level (up to $68.3 \%$ ) and biometrical parameters of the shoots recovered.

Funding: This research received no external funding.

Conflicts of Interest: The author declares no conflict of interest.

\section{References}

1. Roberts, C.M.; Serek, M.; Andersen, A.S. Supplemental irradiance and STS improve the display life of Dicentra species forced as flowering potted plants. Sci. Hortic. 1995, 62, 121-128. [CrossRef]

2. Hodges, L. Bleeding heart: A review for growers. Hort. Technol. 2012, 22, 517-522. [CrossRef]

3. Petruczynik, A.; Plech, T.; Tuzimski, T.; Misiurek, J.; Kaproń, B.; Misiurek, D.; Szultka-Młyńska, M.; Buszewski, B.; Waksmundzka-Hajnos, M. Determination of selected isoquinoline alkaloids from Mahonia aquifolia; Meconopsis cambrica; Corydalis lutea; Dicentra spectabilis; Fumaria officinalis; Macleaya cordata extracts by HPLC-DAD and comparison of their cytotoxic activity. Toxins 2019, 11, 575. [CrossRef]

4. Lee, K.P.; Lee, D.W. Somatic embryogenesis and plant regeneration from seeds of wild Dicentra spectabilis (L.) Lem. Plant Cell Rep. 2003, 22, 105-109. [CrossRef]

5. Lee, K.-S.; Sim, O.-K.; Shin, J.-S.; Choi, Y.-E.; Kim, E.-Y. Mass propagation of Dicentra spectabilis L. Lemaire through in vitro suspension culture. J. Plant Biotechnol. 2004, 31, 121-126. [CrossRef]

6. Kulus, D. Influence of growth regulators on the development, quality, and physiological state of in vitro-propagated Lamprocapnos spectabilis (L.) Fukuhara. In Vitro Cell. Develop. Biol. Plant 2020. [CrossRef]

7. FAO. Climate Change and Food Security: Risks and Responses; FAO: Rome, Italy, 2016; p. 110.

8. Deno, N.C. Seed Germination Theory and Practice, 2nd ed.; Pennsylvania State College: State College, PA, USA, 1993; p. 53.

9. Hammond, H.S.D.; Viehmannova, I.; Zamecnik, J.; Panis, B.; Cepkova, P.H. Efficient slow-growth conservation and assessment of clonal fidelity of Ullucus tuberosus Caldas microshoots. Plant Cell Tiss. Organ Cult. 2019, 138, 559-570. [CrossRef]

10. Muñoz-Miranda, L.A.; Rodríguez-Sahagún, A.; Acevedo Hernández, G.J.; Cruz-Martínez, V.O.; Torres-Morán, M.I.; Lépiz-Ildefonso, R.; Aarland, R.C.; Castellanos-Hernández, O.A. Evaluation of somaclonal and ethyl methane sulfonate-induced genetic variation of Mexican oregano (Lippia graveolens H.B.K.). Agronomy 2019, 9, 166. [CrossRef]

11. Kulus, D. Cryopreservation of bleeding heart (Lamprocapnos spectabilis (L.) Fukuhara) shoot tips using encapsulation-dehydration. CryoLetters 2020, 41, 75-85.

12. Kim, H.H.; Lee, Y.G.; Shin, D.J.; Ko, H.C.; Gwag, J.G.; Cho, E.G.; Engelmann, F. Development of alternative plant vitrification solutions in droplet-vitrification procedures. CryoLetters 2009, 30, 320-334. [CrossRef]

13. Sakai, A.; Kobayashi, S.; Oiyama, I. Cryopreservation of nucellar cells of navel orange (Citrus sinensis Osb. var. brasiliensis Tanaka) by vitrification. Plant Cell Rep. 1990, 9, 30-33. [CrossRef] [PubMed]

14. Aronen, T.S.; Krajnakova, J.; Haggman, H.; Ryynänen, L. Genetic fidelity of cryopreserved embryonic cultures of open-pollinated Abies cephalonica. Plant Sci. 1999, 142, 163-172. [CrossRef]

15. Hosoki, T. In vitro storage of Chrysanthemum morifolium at room temperature. Plant Tissue Cult. Lett. 1989, 6, 86-87. [CrossRef] 
16. Nishizawa, S.; Sakai, A.; Amano, Y.; Matsuzawa, T. Cryopreservation of asparagus (Asparagus officinalis L.) embryogenic suspension cells and subsequent plant regeneration by vitrification. Plant Sci. 1993, 91, 67-73. [CrossRef]

17. Kulus, D.; Zalewska, M. Cryopreservation as a tool used in long-term storage of ornamental species-A review. Sci. Hortic. 2014, 168, 88-107. [CrossRef]

18. Murashige, T.; Skoog, F. A revised medium for rapid growth and bio assays with tobacco tissue cultures. Physiol. Plant. 1962, 15, 473-497. [CrossRef]

19. Kulus, D.; Zalewska, M. In vitro plant recovery from alginate encapsulated Chrysanthemum $\times$ grandiflorum /Ramat./Kitam. shoot tips. Prop. Ornam. Plants 2014, 14, 3-12.

20. Dobránszki, J.; Mendler-Drienyovszk, N. Cytokinin-induced changes in the chlorophyll content and fluorescence of in vitro apple leaves. J. Plant Physiol. 2014, 171, 1472-1478. [CrossRef]

21. Ivanova, M.; Van Staden, J. Influence of gelling agent and cytokinins on the control of hyperhydricity in Aloe polyphylla. Plant Cell Tiss. Organ Cult. 2011, 104, 13-21. [CrossRef]

22. Kulus, D. Application of synthetic seeds in propagation, storage and cryopreservation of Asteraceae plant species. In Synthetic Seeds Germplasm Regeneration, Preservation and Prospects; Faisal, A., Alatar, A., Eds.; Springer: Berlin, Germany, 2019; pp. 155-179.

23. Lineberger, R.D. Shoot proliferation, rooting and transplant survival of tissue-culture 'Hally Jolivette' cherry. HortScience 1983, 18, 182-185.

24. Kulus, D.; Abratowska, A. Cryoconservation of Ajania pacifica (Nakai) Bremer et Humphries via encapsulation-dehydration technique. CryoLetters 2017, 38, 387-398. [PubMed]

25. Popova, E.; Bukhov, N.; Popov, A.; Kim, H.-H. Cryopreservation of protocorm-like bodies of the hybrid orchid Bratonia (Miltonia flavescens $\times$ Brassia longissimi). CryoLetters 2010, 31, 426-437. [PubMed]

26. Jitsupakul, N.; Thammasiri, K.; Ishikawa, K. Cryopreservation of Vanda coerulea protocorm-like bodies by droplet-vitrification. Acta Hort. 2011, 908, 207-214. [CrossRef]

27. Kulus, D.; Serocka, M.; Mikuła, A. Effect of various preculture and osmotic dehydration conditions on cryopreservation efficiency and morphogenetic response of chrysanthemum shoot tips. Acta Sci. Pol. Hort. Cult. 2018, 17, 139-147. [CrossRef]

28. Wang, M.; Zhang, Z.; Zámečník, J.; Bilavčík, A.; Blystad, D.-R.; Haugslien, S.; Wang, Q.-C. Droplet-vitrification for shoot tip cryopreservation of shallot (Allium cepa var. aggregatum): Effects of PVS3 and PVS2 on shoot regrowth. Plant Cell Tiss. Organ Cult. 2020, 140, 185-195. [CrossRef]

29. Vianna, M.G.; Ferreira, A.L.; Garcia, R.O.; Falcão, E.; Pacheco, G.; Mansur, E. Comparison of vitrification-based techniques in the efficacy of cryopreservation of Passiflora suberosa L. and P. foetida L. shoot tips. Cryobiology 2012, 65, 346. [CrossRef]

30. Liu, Q.; Luo, L.; Zheng, L. Lignins: Biosynthesis and biological functions in plants. Int. J. Mol. Sci. 2018, 19, E335. [CrossRef]

31. Mikuła, A.; Tykarska, T.; Kuraś, M. Ultrastructure of Gentiana tibetica proembryogenic cells before and after cooling treatments. CryoLetters 2005, 26, 367-378.

32. Pawłowska, B.; Szewczyk-Taranek, B. Efficient cryopreservation by droplet vitrification of pentaploid roses and the phenotype of regenerated plants. Acta Soc. Bot. Pol. 2015, 84, 439-442. [CrossRef]

(C) 2020 by the author. Licensee MDPI, Basel, Switzerland. This article is an open access article distributed under the terms and conditions of the Creative Commons Attribution (CC BY) license (http://creativecommons.org/licenses/by/4.0/). 